\title{
LA DINAMICIDAD DE LOS TEXTOS LITERARIOS: HACIA UNA TIPOLOGÍA DE LA TRANSREFERENCIALIDAD ${ }^{1}$
}

\author{
THE DYNAMICITY OF LITERARY TEXTS: \\ TOWARDS A TIPOLOGY OF TRANSREFERENTIALITY \\ José Ángel BAÑOS SALDAÑA \\ Universidad de Murcia \\ joseangel.banos@um.com
}

\begin{abstract}
Resumen: Este artículo integra las aportaciones de la teoría de la literatura acerca de las relaciones entre los textos en un contexto más abarcador: el de la transacción de referencias. De este modo, se contemplan las particularidades de los vínculos que fomentan las obras literarias, incluyendo aquellos que se producen con elementos no textualizados - sistemas semiológicos distintos o esquemas formales o de contenido, por ejemplo-. En consecuencia, se propone una tipología sobre los procedimientos transreferenciales, que se estructuran en tres niveles: 1) el contacto directo, 2) las modalidades, y 3 ) las relaciones interdiscursivas. Esta clasificación, susceptible de aplicarse a todos los géneros, se ejemplificará a lo largo del artículo con textos pertenecientes a la poesía española contemporánea.
\end{abstract}

Palabras clave: Transreferencialidad. Transtextualidad. Intertextualidad. Posmodernidad. Poesía española contemporánea.

\begin{abstract}
This paper integrates the contributions of literary theory about the relationships between texts in a wider context: that of the transaction of references. In this way, it contemplates the particularities of the links fostered by literary works, including those produced by means of non-textualised elements (different semiotic systems or formal or content schemas, for example). Consequently, a typology is proposed regarding transreferential procedures, which are structured on three levels: 1) direct contact, 2) modes, and 3) interdiscursive relations. This classification, which can be applied to all genres, will be exemplified throughout the paper with texts belonging to contemporary Spanish poetry.
\end{abstract}

Keywords: Transreferentiality. Transtextuality. Intertextuality. Postmodernism. Contemporary Spanish Poetry.

\footnotetext{
${ }^{1}$ Esta investigación ha sido realizada con el apoyo de una ayuda para la formación del profesorado universitario del Ministerio de Ciencia, Innovación y Universidades (FPU17/02461).
} 


\section{LA TRANSREFERENCIALIDAD COMO PROPUESTA TIPOLÓGICA}

El examen de la historia de la teoría sobre las relaciones que establecen los textos evidencia que para alcanzar un grado notable de conocimiento se requiere una tipología que clasifique el comportamiento de las obras literarias. Bien es cierto que no se trata de una materia dócil ni exenta de dificultades, pero la suma de obstáculos no justifica que el crítico rinda las armas filológicas. Recuérdese que la artillería transtextual ${ }^{2}$ nació en el seno del debate sobre la intertextualidad. Si se piensa en el surgimiento de esta tipología, se aprecia que los teóricos trataron de acabar con un gran vacío: la ausencia de un repertorio de mecanismos textuales que facilitaran el entendimiento del dinamismo literario; dicho de otro modo, la aparición de tipologías como la de la transtextualidad (Genette, 1989) y, sobre todo, su éxito posterior constatan que llegó un momento en el que la crítica se convenció de que había descuidado la riqueza con la que la cultura se comunica.

Ahora bien, era tanta la pertinencia de una clasificación como la de Palimpsestos que en cierta medida desencadenó un efecto no previsto por su autor. La inamovilidad de determinados conceptos y la confluencia de estudios sobre el mismo tema, pero provenientes de varias naciones ${ }^{3}-\mathrm{y}$, por lo tanto, escritos en lenguas distintas-, han acumulado datos que, aunque de indiscutible relevancia, han pasado por alto algunos matices de fábrica que deben enmendarse. Por otra parte, los estudios de este fenómeno a veces se han referido a un mismo proceso con nombres opuestos o, al contrario, han englobado estrategias o recursos disímiles bajo una misma denominación ${ }^{4}$. Sucede, incluso, que en no pocas ocasiones se han descuidado los aspectos más sencillos, de manera que se ha prolongado una imprecisión teórica que, ya sea por costumbre o por mantener intacta la historia de la disciplina, ha preferido obviarse, como ha pasado con el protagonismo de la palabra texto en la tipología genettiana.

Así las cosas, se ha sostenido con frecuencia la existencia de una intertextualidad pictórica o una intertextualidad musical cuando ni la pintura ni la música son textos. En esos casos cabría plantear el análisis de una voluntad discursiva, pero nunca se limitarán por naturaleza al ámbito de lo textual, ni siquiera cuando los signos gráficos o sonoros recurran al empleo de la lengua. La fagocitación de este tipo de deslizamientos entre sistemas por parte de lo escrito debería prevenirnos de la confusión que genera una tipología que abunda exclusivamente en lo textual a través de cinco categorías que le otorgan superioridad a las cuestiones del texto. Estas consideraciones ya las concebía el propio Genette (1989), que insistía en que la literatura se relaciona con otras artes. En

\footnotetext{
${ }^{2}$ La transtextualidad es una tipología de cinco niveles propuesta por Genette (1989): la intertextualidad, la paratextualidad, la metatextualidad, la hipertextualidad y la architextualidad.

${ }^{3}$ Algunos investigadores, de hecho, han clasificado las aportaciones a la teoría de la intertextualidad a partir de un criterio geográfico (Navarro, 2004).

${ }^{4}$ Lara Rallo, por ejemplo, ha señalado la dispersión teórica del concepto de intertextualidad: "hasta el punto de que puede interpretarse que su significado en cada corriente crítica está sujeto al deseo de cada autor o al modo en que individualmente es interpretado por cada crítico" (2006: 24).
} 
definitiva, y como preveía el teórico francés, hay que confeccionar un esquema organizativo que no solo cuente con las relaciones de lo escrito, sino también con aquellas en las que el texto reclama los medios o los recursos de otros sistemas semiológicos - las interartísticas, intersemióticas o interdiscursivas-. Bianchi (2017) señala que, de los significados del prefijo trans- ('al otro lado de' y 'a través de'), Genette profundizó en el segundo, si bien el primero es igualmente importante.

La tipología de los vínculos que fomentan los textos es susceptible de construirse a partir de alguno de los ejes de la cultura contemporánea, que ha auspiciado diversas clasificaciones aproximativas y en la que no por azar se han acuñado nociones como la de intertextualidad y se han desarrollado otras como las de parodia o pastiche. Y esta columna marmórea del contexto actual se corresponde con una de las bases del posmodernismo: la referencialidad. Si la literatura contemporánea durante el siglo XX acentúa notoriamente la autorreflexión y la autoconsciencia, al mismo tiempo que vuelve su mirada hacia la tradición y hacia la transmisión del mundo como texto o hacia su irredenta e imposible subyugación de la realidad a las palabras (Baños Saldaña, 2019), la raíz de las relaciones textuales no se halla en la comunicación entre textos, sino que se encuentra en un fenómeno de mayores dimensiones: la transacción de referencias. Esto conlleva la evolución de la transtextualidad a una transreferencialidad, entendida como la 'trascendencia referencial de los textos'. Volviendo sobre los dos valores del prefijo trans-, la transreferencialidad deviene en un método rentable para el análisis de una literatura cruzada que realza las intersecciones de referentes a través de un mismo circuito - el escrito-, y que también exhibe los nexos entre referencias ubicadas al otro lado de la frontera de la letra impresa — otras artes o medios de comunicación, por ejemplo-.

La estructura de la tipología transreferencial se forja a partir de un criterio descendente de aproximación referencial, de manera que se han configurado tres niveles: de ellos, el primero es el que aporta mayor cercanía objetual, mientras que el tercero es el que funciona según una menor proximidad con la materia del producto resultante. La presentación de los tres estadios en forma de esquema ayuda a la comprensión de la tripartición teórica:

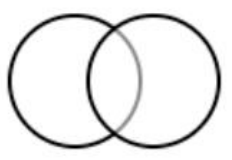

Nivel 1



Nivel 2

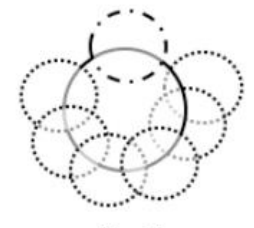

Nivel 3

Esquema 1. Niveles de la tipología de la transreferencialidad:

1) contacto, 2) modalidad, y 3) interdiscursividad [elaboración propia]

En el primer nivel se agrupan las operaciones por contacto directo con el referente. El esquema representa la simplificación total del proceso, pues en realidad el texto presente supedita un fragmento referencial que no ha de replicar o ni siquiera de corresponderse obligatoriamente con el del origen del préstamo. Esta ilustración, en definitiva, pretende 
resaltar la conexión entre dos referentes independientes. Si se trata de un vínculo meramente textual, nos hallamos ante situaciones de intertextualidad, intratextualidad, reescritura o paratextualidad. Si, por el contrario, el contacto se produce entre un texto $\mathrm{y}$ un referente perteneciente a otro sistema semiológico o multimedial, se trata de un proceso de intermedialidad.

El segundo nivel concierne a la creación sustentada por modalidades como la parodia o la sátira paródica. Su particularidad reside en que incluyen un contacto directo — primer nivel - y mantienen una tensión discursiva - tercer nivel—, pero no se restringen a una sola operación de las dos citadas. Tampoco se identificará como la suma de ambos procesos, pues se entendería que funcionan independientemente. Lo vital de las modalidades transreferenciales es que juegan en los dominios que hemos señalado con la línea de puntos en el esquema: son, al mismo tiempo, intertextuales y metadiscursivas, por lo que se localizan en el lugar intermedio de ambos niveles.

La tercera ilustración conduce al último estadio, el de la reproducción de esquemas formales y de contenido, también comprendidos como interdiscursividad. En este caso, el texto literario no se apropia de una porción concreta del producto objetivo, sino que busca en él sus patrones organizativos. Se trata, entonces, de un mecanismo más trascendente y abstracto que el simple contacto directo entre las partes de dos obras. Aquí se encasillarían las relaciones entre un texto y una referencia estructural, como ejemplifica en el esquema la presentación de un círculo grande y otro más pequeño bordeado con rayas y puntos. Sin embargo, cabe atender a la posibilidad de que no se reproduzca un solo esquema, sino que se utilicen como referentes otros muchos, que incluso podrían compartir propiedades. Y esto queda representado en la ilustración a través de círculos punteados. Responden a la transreferencialidad interdiscursiva fenómenos como el pastiche, la interfiguralidad o las variantes tematológicas.

La estructuración global de esta tipología no se desentiende de la problemática derivada de la estratificación rigurosa. Parece casi innecesario apuntar que, a pesar de que las categorías transreferenciales se proponen como una organización compleja y eficiente para las relaciones del texto, la literatura es un producto cultural vivo que funciona a través de transferencias y mixturas. Es por esto por lo que no se niega la combinación de elementos, sobre la que, además, la tipología podrá dar cuenta. Por ejemplo, dentro de un mismo nivel habrá fusiones, como sucede con la apropiación de un texto procedente de un referente periodístico $-\mathrm{y}$, por tanto, multimodal-; y también las habrá entre diferentes estadios, como una parodia que recurra a actualizaciones interfigurales.

De manera general, puede señalarse la siguiente paradoja: la transreferencialidad es aquello de lo que siempre se ha hablado, pero que nunca ha sido dicho; esto es, la crítica ha recogido una gran variedad de procesos literarios bajo la denominación de intertextualidad, que en realidad afecta a un fenómeno muy concreto, para reflexionar sobre los vínculos que fomentan los textos. No ha de extrañar, pues, que de la reacomodación de las consideraciones en torno a la intertextualidad se logre el planteamiento de un corolario transreferencial mínimo, que se resume en siete postulados: 
1) la transreferencialidad constituye una tipología que responde a las exigencias de la operatividad crítica, por lo que todo proceso transreferencial se identifica en textos concretos y nunca quedará en manos de las casualidades genéricas o de la imaginación del lector;

2) la transreferencialidad implica siempre una conexión explícita con una referencia anterior a la que se denominará hiporreferente - concepto que no discrimina ninguno de los tres niveles - para resaltar la singularidad referencial del texto;

3) la transreferencialidad pone en marcha todo el circuito literario a través de especificaciones que conciernen a sus cuatro figuras nucleares, que se desglosarán en las cuatro siguientes máximas;

4) el autor de un texto transreferencial lleva a cabo un proceso de suspensión de la autoría y de ruptura no de la linealidad, ya que finalmente resulta un producto lineal, sino de la individualización de la obra en favor de la superposición o de la simultaneidad referencial. Este controlará, pues, la doble coherencia que Plett (2004) otorgaba a los intertextos; es decir, el hiperreferente, concepto acuñado por oposición al de hiporreferente ${ }^{5}$, gozará de una coherencia para consigo mismo — intratextual — y para con los hiporreferentes - extratextual-;

5) el autor de un hiperreferente se concentrará en el protagonismo textual de su obra. Así, dedicará especial atención a la verbalización de la hiporreferencia y a su incrustación en el nuevo molde. Este paso no está exento de particularidades a nivel pragmático, dado que el interreferente se descontextualiza para recontextualizarse en el hiperreferente. Por tanto, los préstamos pueden llegar intactos o ser transformados significativamente por el autor;

6) tanto la autoría como la textualidad de los hiperreferentes salvaguardan el proceso comunicacional actuando sobre el horizonte de expectativas con objeto de encarrilar la lectura. De este modo, el receptor no se topa con un texto monolítico, sino que se enfrentará a un producto dinámico que, en los casos de mayor pertinencia semiósica, concederá tanta importancia al significado como al sentido;

7) más allá del lector y de la lectura, en sus acepciones más cotidianas, el valor de los mecanismos transreferenciales exige un intérprete especializado que lo desentrañe y que, a su vez, lo incardine en el conjunto de una poética para ampliar el conocimiento sobre el alcance y el curso de la historia literaria y, sobre todo, para seguirle el rastro a la evolución de los referentes artísticos.

En definitiva, además de su alto rendimiento crítico-literario, otra de las ventajas de la teoría de la transreferencialidad es que integra de modo ordenado muchas de las consideraciones previas en torno a las relaciones textuales. Genette anotaba con humor al principio de Palimpsestos que "[v]a siendo hora de que un Comisario de la República de

\footnotetext{
${ }^{5}$ Utilizamos los términos hiporreferencia e hiperreferencia como actualizaciones de los de Genette (1989), hipotexto e hipertexto. Como el hiporreferente remite a la referencia fuente, se requiere un concepto alternativo que, al igual que el de intertexto, dé cuenta de la manipulación del referente previo que se insertará en el hiperreferente. A esta noción la denominaremos, también por analogía, interreferente.
} 
las Letras nos imponga una terminología coherente" (1989: 9). Decía esto al descubrir que otro teórico había empleado antes que él la noción de architextualidad con distinto sentido. Lo cierto es que la broma del francés para atenuar la importancia de su desmarque conceptual se ha convertido en una suerte de chiste que resulta menos gracioso a medida que se repite. Se trata de una cuestión que afecta al centro de la teoría de la literatura y a la pugna académica por reconocer su estatuto científico. Con la propuesta transreferencial se recogen los mecanismos de mayor operatividad y rigurosidad que hasta ahora ha aportado la teoría, y se disponen en un marco de aplicación más amplio.

\subsection{El contacto directo del texto con su referente: la intertextualidad y la intermedialidad}

Los patrones transreferenciales de contacto directo se han agrupado en dos direcciones de acuerdo con las particularidades del referente. Desde esta postura, se delimitan claramente el espacio textual y el intersemiótico. Si la relación se efectúa entre dos textos, la denominamos intertextualidad; en cambio, si tal vínculo lo consolida un texto con un referente no verbal o verbal, pero acompañado de otros sistemas semiológicos —anciones, vídeos, publicidad, entre otros-, lo consideraremos intermedialidad. A partir de este criterio, será posible la distinción precisa de las especies que cada grupo acoge, lo que repercute inevitablemente sobre la eficiencia crítica.

\subsubsection{La intertextualidad, la intratextualidad, la reescritura y la paratextualidad}

Aunque la teoría de la intertextualidad ha invertido gran parte de su tiempo en la sofisticación de un concepto simple, y con ello ha impulsado nuevos debates en torno al hecho literario, su definición se circunscribe al ámbito de las relaciones más palpables, aquellas que se ocasionan por contacto directo. De hecho, para llegar a su significado esencial, no es necesario evolucionar la noción; al contrario, conviene ajustarla a un efecto involutivo que le devuelva la concisión y la popularidad de las palabras de Genette (1989), quien la limita a un proceso práctico de copresencia de un texto en otro. Sirva de prueba la siguiente reacomodación del verso de Quevedo en una parte del poema "Anuncios", de Aurora Luque: "Soy No-fui, No-seré, No-soy cansado" (2003: 50).

Acompañando al concepto de intertextualidad, se ha difundido el de intratextualidad, que funciona de la misma manera excepto porque la hiporreferencia en este caso será un texto redactado previamente por el propio autor del hiperreferente (Martínez Fernández, 2001). Al igual que las otras categorías por contacto directo, esta se usa en numerosas ocasiones. Ahora bien, se vuelve especialmente relevante cuando les sirve a los escritores para revisar su trayectoria, como sucede en Cantos de vida y esperanza, de Rubén Darío, por ejemplo.

La reescritura actúa como otro procedimiento por adhesión a la materialidad del hiporreferente. Equivale a la intertextualidad o a la intratextualidad, pero añade la 
condición de que debe persistir de forma continua en la reproducción de la hiporreferencia; esto es, la interreferencia se expande ostensivamente en el hiperreferente porque supone la revisión de un texto no cercenado a un pequeño fragmento. Protagonizan las reescrituras aquellos poemas que siguen el flujo de los enunciados resultantes de un texto previo. Véase “Otro poema de los dones”, de José María Álvarez, que utiliza como plantilla el texto homónimo de Borges. Ofrecemos aquí un extracto que representa la totalidad del poema:

Gracias quiero dar al sagrado

Azar, o al Libro donde todo estaba escrito,

Por la diversidad de las criaturas

Que forman este singular Universo,

Por la razón, que no cesará de soñar,

Por el rostro de Elena y la perseverancia de Ulises,

[...] (2002: 746).

Finalmente, la paratextualidad quedará comprendida en los términos de Genette (2001). Se concederá un mayor grado de operatividad a la separación de las categorías según la posición textual, de manera que los recursos paratextuales se dividen en los epitextuales y los peritextuales. El epitexto engloba todos los fenómenos que suceden alrededor del texto - es decir, fuera del libro-. El peritexto, sin embargo, recoge las conexiones que se producen con elementos periféricos; esto es, alude a aquellas relaciones con elementos insertos en la obra literaria concreta. Cabría anotar una precisión: para las conexiones establecidas con recursos no textuales, habrá que situar la teoría en las coordenadas transreferenciales, dando lugar a la pararreferencialidad, que se divide en la epirreferencialidad y la perirreferencialidad. No obstante, en estos casos se hibridará la tipología con otros mecanismos de contacto directo.

\subsubsection{La intermedialidad: el contacto entre un texto y otro sistema semiológico}

Puesto que la obra literaria nace de las palabras, la mayoría de las apropiaciones terminarán adquiriendo una forma textual. No ha de extrañar que la intertextualidad y la intermedialidad se hayan tratado casi como equivalentes, pues comparten puntos esenciales. El más elemental es la operación por contacto directo: como hemos visto, la intertextualidad se limita a la recolección de un texto por parte de otro; de igual manera, la intermedialidad literaria implica el préstamo $\longrightarrow$ el robo- de algún elemento perteneciente a otro medio. En este sentido, la intermedialidad se comporta como un mecanismo intersemiótico (Pimentel, 2003), lo que supone que generalmente lleve aparejada una serie de referencias o de matices añadidos que la intertextualidad no incorpora. Tómese como ejemplo la publicidad, cuya fusión de medios la convierte en un género de segundo grado - necesita de otros muchos géneros: música, imagen, texto-. Cuando una obra literaria añade un elemento publicitario, este se recibirá primero como texto, pero prácticamente de forma simultánea atraerá efectos acompañantes que se 
derivan de lo visual y de lo sonoro (Baños Saldaña, 2020). En definitiva, tratar la intermedialidad como intertextualidad cercena la interpretación, ya que la subyuga al molde de lo escrito y deja de lado, así, todo el entramado cultural e intersemiótico que activa. A este respecto, piénsese en el poema "Contra-orden", de Ángel González, que toma como base el eslogan ("Mantenga limpia España") y las imágenes de una serie de anuncios nacionales para el fomento de la limpieza en las calles.

Con todo, desde los inicios del término los críticos lo han vinculado a la intertextualidad. Aun siempre recelosos, pues no se aborda la relación entre textos, se conformaron con el establecimiento de esta similitud para impulsar la nueva noción aprovechando el prestigio de aquella vecina: "What is intermediality? A short answer would be: a sadly neglected but vastly important subdivision of intertextuality" (Wagner, 1996: 17). Por entonces se intentó consolidar el término gracias al auge de la teoría de la intertextualidad $^{6}$, que se contemplaba como la piedra angular de la literatura, y gracias, también, a la concepción muy amplia de texto y de lenguaje derivada de las teorías semióticas. Hay que recordar que para Lotman "[t]odo sistema que sirve a los fines de comunicación entre dos o numerosos individuos puede definirse como lenguaje" (1978: 17-18).

Estos enfoques, que consideran la intermedialidad como un producto manufacturado a imagen y semejanza de la intertextualidad, se benefician de sus avances teóricos para asentar el concepto. Ahora bien, la adopción de esta conducta se comporta de forma demasiado benevolente con la intertextualidad como resultado teórico con apetito saturnal. Muchos estudios intertextuales no solo han devorado las subdivisiones planteadas a partir de ellos, sino que también han fagocitado otras nociones anteriores a su existencia. Más allá de la popularidad de la teoría intertextual y de la coincidencia en el procedimiento por contacto, cabe preguntarse por el motivo que alumbra la creciente necesidad de vincular la definición de la familiaridad entre sistemas a la de las colisiones textuales, hasta el extremo, incluso, de pensar que la intermedialidad depende de la intertextualidad. Y la razón que se puede aducir a esto es que no se ha comenzado su análisis desde una perspectiva cultural en la que, teniendo en cuenta la alta frecuencia de las relaciones del texto y de la reflexión sobre los nuevos sistemas semiológicos, se organicen los desplazamientos artísticos en función de un caldo de cultivo transreferencial. Así se comprende mejor que manejamos patrones teóricos vecinos, pero no dominados uno por otro, sino que ambos se insertan en un sistema de organización más amplio en el que desempeñan el rol de las operaciones estrechamente unidas a su referente.

La creación de carácter intermedial ha abundado a lo largo de los siglos; de hecho, su forma más conocida, la écfrasis, se remonta a la Antigüedad. Esta técnica siempre ha estado relacionada con lo visual (Bagué Quílez, 2012); no obstante, progresivamente ha abierto dos sendas de análisis: la que unió el concepto a un procedimiento literario de

\footnotetext{
${ }^{6}$ Además del trabajo de Wagner, véanse Riffaterre (2000), Pimentel (2003), Plett (2004) o Giovine (2011).
} 
descripción de las artes plásticas ${ }^{7}$ y la que ensancha el alcance ecfrástico a otros sistemas que no guardan relación con la imagen ${ }^{8}$. En cualquier caso, la écfrasis constituye un movimiento intermedial que atañe a la propia relación de la literatura con su entorno, de ahí, también, su asiduidad en la lírica española reciente.

Al margen de los debates sobre la preponderancia de unos medios u otros, es un hecho constatable que las interferencias entre las artes del tiempo y del espacio han ocupado uno de los lugares más importantes en la cultura contemporánea. Si bien la ingente producción ecfrástica o intermedial exige un consenso crítico, lo cierto es que se ha producido una considerable dispersión tipológica. La mayoría de clasificaciones del texto ecfrástico ahondan en la problemática referencial, pero no establecen un acuerdo terminológico. Una vez más, puede observarse que a los teóricos les preocupa un asunto de índole transreferencial; sin embargo, optan por identificar múltiples vías cuando, realmente, lo que se analiza es si la obra literaria reproduce la imagen o, por el contrario, genera una interpretación. En principio, todo lo demás debería quedar fuera de los dominios de la écfrasis, pues esta ha de remitir al objeto en vez de a su artífice o a su espectador ${ }^{9}$. Como ejemplo, puede leerse "La dama de Warka”, de José María Álvarez:

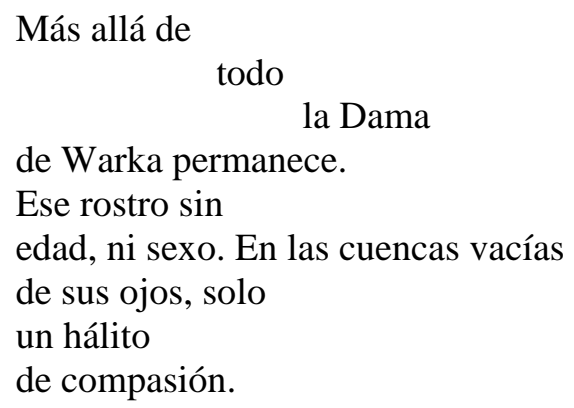

Dice el Museo de Bagdad que era una sacerdotisa de sangre real. Era un rostro para el artista en ese instante en que nos dimos cuenta de que solo tienen ya sentido la piedad y el orden (2002: 740).

Riffaterre nunca extrapola el núcleo de la discusión a la transreferencialidad, pero sí que define la écfrasis como una "ilusión referencial":

\footnotetext{
${ }^{7}$ Con el tiempo la écfrasis abandonó su sentido primigenio derivado de las prácticas retóricas. En lo que concierne al desarrollo de la noción por la teoría de la literatura contemporánea, cabe mencionar la influencia de Spitzer, que impulsó la nueva perspectiva al clasificarla como "the poetical description of a pictorial or scuptural work of art" (1962: 72).

8 Se ha convertido en un lugar común teórico allegar al concepto de écfrasis solamente a las intermediaciones visuales; no obstante, han surgido corrientes de pensamiento que amplían el efecto ecfrástico a la imbricación de otros sistemas, como sucede con la relación entre literatura y música (Bruhn, 2011; Velarde Sánchez, 2018).

9 Para estos últimos procedimientos, Ponce Cárdenas ha proporcionado el concepto de textos "paraecfrásticos" (2014: 31).
} 
Como el texto ecfrástico representa con palabras una representación plástica, esta mímesis es doble. Pero también es ilusoria, ya sea porque su objeto es imaginario, o bien porque su descripción tan solo hace visible una interpretación dictada menos por el objeto real o ficticio que por su función en un contexto literario (2000: 161).

Dadas estas particularidades del texto ecfrástico, el teórico francés insistirá en que la literatura no traduce una imagen a palabras, sino que se trata de un movimiento mucho más obvio, cuyo análisis detenido devuelve una comprensión eficaz del asunto: la écfrasis creativa reemplaza el cuadro - lo óptico, en general - por un texto, con todo lo que eso supone.

De forma global, se percibe que la écfrasis se inserta por naturaleza en el marco de los procedimientos transreferenciales. Su tipología no requiere de una excesiva artificiosidad teórica, pues lo vital es que el texto ecfrástico se comporte como una representación hermenéutica de un referente - real o inventado - que pertenezca a otro sistema semiológico. Resulta interesante la síntesis de Ponce Cárdenas (2014), que la describe como un mecanismo de visión, primero, y luego de escritura. Con el fin de incorporar la écfrasis musical, podría añadirse otra causa - la escucha - que genere la misma reacción - la escritura-

\subsection{Modos transreferenciales: la parodia y la sátira paródica}

Una de las vías transreferenciales más comunes en la poesía española contemporánea es la parodia, que suele relacionarse inintencionadamente o confundirse con la sátira y con el pastiche. Tanto la sátira como la parodia ejercen una mayor influencia -incluso ocupan más extensión - que muchas estrategias y recursos literarios. Asimismo, ambas prácticas artísticas pueden determinar la estructura de una obra compuesta en cualquier género o ejercer una influencia decisiva en el desarrollo de la temática. Ni la sátira ni la parodia se manifiestan exclusivamente en la lírica, en la narrativa o en el teatro. Son, pues, modalidades que, además, comparten el impulso irónico. Junto a ellas, debe prestarse atención al pastiche, que no siempre se construye a través de la ironía y que tampoco mantiene la trascendencia estructural de la parodia ni de la sátira. El pastiche literario se responsabiliza en menor grado de la tensión estructural, pues una obra de gran dimensión enteramente gobernada por este deterioraría el vínculo que había establecido con el lector al provocar un efecto de cansancio. Este mecanismo, que sin duda es cercano a la parodia o a la sátira paródica, se clasificará dentro del tercer nivel transreferencial, como argumentaremos más adelante.

Una parte del éxito de estas modalidades transreferenciales en la literatura española contemporánea se halla en su anclaje irónico. $\mathrm{Si}$, como venimos advirtiendo, los poetas tematizan el proceso de relación textual o de vínculo referencial, la ironía se presta favorablemente a los juegos de voces o de ambivalencias, ya que mediante un enunciado 
es capaz de señalar múltiples referentes. De este modo, la ironía pone en marcha una serie de remisiones que van desde lo explícito a lo implicado.

La ironía, relativamente poco estudiada en la lírica, apoya las tentativas de insertar el texto poético en la realidad. Los escritores la emplean, entonces, para deshacerse de una concepción literaria excesivamente ingenua (Bagué Quílez y Rodríguez Rosique, 2013) o anacrónica, fruto del automatismo amparado por la acumulación de obras antiguas en el canon. No han de extrañar, por tanto, juicios como el de Pere Ballart: "decir poesía moderna es decir poesía [...] irónica" (2005: 236). En lo que respecta a la ironía paródica, que posee una faceta más relacional que la satírica, cabe mencionar que suele dejar en suspensión la seriedad de la hiporreferencia para que la hiperreferencia recuerde que la anterior ponía un exceso de confianza en el poder transformador de la palabra, en la imagen - casi oracular - del poeta o en la visión sacralizada de la lírica. En general, se trata de una confrontación entre el carácter idealizado de la primera referencia y la exacerbada realidad de la segunda (Ballart, 1994).

La ironía no solo ha formado parte de las discusiones académicas, sino que ha captado el interés de los propios escritores, quienes han aprovechado las entrevistas y otros espacios extraliterarios para justificar su estilo. Estos coinciden en el retrato robot de la veta irónica, cuya silueta la conforman la ambigüedad, el realismo, el enfoque perspectivístico y el contraste entre las expectativas individuales y el resultado social. Véase la siguiente declaración de Ángel González:

la vida es un complejo de contradicciones. Nada es solo una cosa, y todo tiene dos caras. Y así es la vida: por una parte, hay muchos motivos para la esperanza, pero también hay muchos motivos para el pesimismo. Por eso la ironía, que creo que es un rasgo característico de mi expresión poética... Yo insisto la ironía... porque es capaz de expresar de una sola vez, de un solo golpe, esa ambigüedad. La ironía es capaz de decir el sí y el no a la vez acerca de las cosas. Y así es - creo yo- la vida, una relación dialéctica entre lo que esperamos, como esperanza, y lo que nos defrauda, nos decepciona (2014).

Más allá de los escritores y de la crítica, el comportamiento irónico se ha descrito desde la filosofía, también, como uno de los fundamentos de la contemporaneidad. Esta línea de pensamiento se adhiere a la sociedad digitalizada, en la que el individuo participa en una conversación pública de masas tendente a las polaridades ideológicas. A este respecto, Gerchunoff (2019) analiza las causas de la ironía contemporánea, a la vez que rechaza la postura antiirónica para defender la comunicación masificada actual. Este filósofo sintetiza tres rasgos que caracterizan a la ironía desde sus orígenes. Estos tres aspectos, que vincula a la comunicación de masas, también sirven para la descripción de la literatura: la ironía es "humilde" —o simula humildad_, "reaccionaria" —implica una oposición - y "política" — interviene en un marco social—. Trasvasado esto a la lírica, el comportamiento irónico acentúa la raigambre histórica y cultural de la creación poética, pues la ironía por sí sola — o la que engendra a la parodia o a la sátira — se comprenderá mejor cuanto más se conozca el contexto en el que se produce: 
Las reconstrucciones de la ironía no se pueden reducir casi nunca, o nunca, a gramática o a semántica o a lingüística. Al leer cualquier ironía que valga la pena tener en cuenta, leemos la vida misma, y al abordarla nos basamos en nuestras relaciones con los demás (Booth, 1986: 78).

Las ironías verbales, que son las más aprovechables desde la motivación transreferencial, son "enunciaciones polifónicas" en las que interacciona el pensamiento del hablante y el de otra u otras personas diferentes (Reyes, 1984: 154): "el hablante se desliga de la opinión de la que se hace eco e indica que no la respalda" (Sperber y Wilson, 1994: 292). Nos situamos, pues, en el terreno de la polifonía textual (Bajtín, 1986; Ducrot, 1986), como venía advirtiendo Barthes al relacionar la ironía con una voz alterna o al señalar el cruce de voces que deviene escritura dentro de un "espacio estereográfico" (1980: 16).

El marco pragmático de la ironía se resuelve analizando la interconexión de los componentes básicos del proceso comunicativo ${ }^{10}$ :

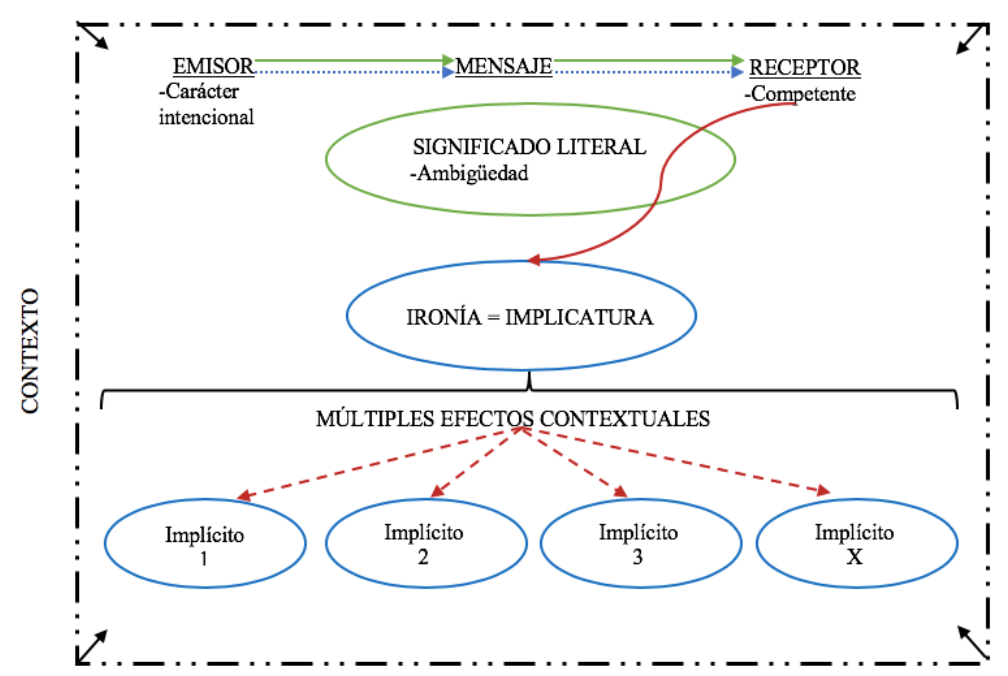

Esquema 2. Funcionamiento de la ironía verbal [elaboración propia a partir de Baños Saldaña, 2017]

Hay que partir, por tanto, de la emisión del mensaje. El hablante — o poeta — plantea un contenido literal que va acompañado de una serie de implícitos a los que llegará el receptor gracias a su competencia. Este, incluso, podría añadir algún significado implícito que el hablante no había preconcebido. En cualquier caso, lo importante es que la ironía ya no se entiende en el sentido clásico de lo contrario a lo que se dice, sino que también se destaca con ella lo que se manifiesta literalmente. Acierta, pues, Hutcheon al considerar

\footnotetext{
${ }^{10}$ Para configurar este marco, he tomado como referencia la teoría de Graciela Reyes: "[p]artiré de la idea de que la ironía es un fenómeno pragmático: solo se percibe en contexto, y depende de las intenciones del locutor y de las capacidades interpretativas del interlocutor. Pragmáticamente, el significado irónico es una 'implicatura' (implicature)" (1984: 154).
} 
que "irony participates in parodic discourse as a strategy, $[. .$.$] which allows the decoder$ to interpret and evaluate" (2000: 31).

El lector del texto irónico —o de las modalidades transreferenciales que la ironía suscita - debe trascender el significado literal hasta desentrañar el significado implicado. Generalmente, los mecanismos irónicos fomentan la consolidación de pactos de lectura que fortalecen la complicidad con el lector (Ballart, 2005; Bagué Quílez y Rodríguez Rosique, 2013). Numerosos autores han puesto énfasis en que el lector debe reconocer la ironía para comprender la sátira y la parodia (Domínguez Caparrós, 1994; Blesa, 1994). Tampoco habría que olvidar la importancia con la que el contexto o los marcos situacionales intervienen en la comunicación; de hecho, el conocimiento compartido y el entorno le facilitan al lector decantarse por una u otra interpretación.

La confusión o la proximidad entre parodia y sátira, por tanto, tienen una explicación de base teórica: ambas modalidades necesitan la ironía para funcionar correctamente. Ahora bien, esta entraña común no justifica el descuido de sus particularidades. Ballart (1994) indica que la ironía es de naturaleza intratextual; la sátira, extratextual; y la parodia, intertextual. Esta descripción se hace efectiva para la visión general de sus principios constructivos. En otro momento añadirá que la parodia es el resultado de sumar ironía e intertextualidad, mientras que la sátira consiste en la mezcla de ironía y vindicación, término que ha de entenderse como la defensa de una postura frente al característico escepticismo de la parodia. A pesar de la claridad de estas valoraciones, cabe advertir dos matices. Por un lado, la parodia no solo responde a la intertextualidad, sino que también activa un complejo mecanismo intratextual para mantener la tensión a lo largo de una obra. Este es el motivo por el que frecuentemente podemos decir que se parodian un texto concreto $\mathrm{y}$, a la vez, todas las especies literarias en las que se inserta dicho texto. Por otro lado, siempre que se junten intertextualidad e ironía no se genera una parodia directamente, pues también la sátira podría aprovechar tales recursos. Se debe profundizar, por tanto, en esos componentes para delimitar las dos modalidades.

Para ello, conviene asentar primero una caracterización más completa de la parodia, debido, principalmente, a que su aparición pone en marcha un dispositivo relacional, mientras que la sátira no ejerce tal dinámica obligatoriamente. La clave se halla en la modulación de la transreferencialidad que ejerce el autor de la parodia. De acuerdo con el proceso comunicativo de la literatura, la parodia posee unas características interrelacionadas. Así, tomando como inicio los criterios de emisión, de enunciado y de recepción, se logran comprender sus tres principios - la "intencionalidad", la "hipertrofia" y la "interpretación"-, que, reunidos, cimientan la comicidad (GarcíaRodríguez, 2021: 140-148).

En definitiva, toda obra paródica remite a un modelo previo, del cual puede, incluso, extraer su esquema como prototipo genérico o tipológico; es decir, la hipertrofia opera sobre una hoja de ruta preexistente, pero le añade desvíos, encrucijadas y caminos independientes. En esta línea, se ha extendido en el debate académico la reflexión de BenPorat acerca de la parodia como representación de una "realidad modelada". Hutcheon 
(2000), por ejemplo, apoya esta idea de que la parodia interviene en el dominio artístico, mientras que la sátira cumple con un objetivo extraverbal. Ben-Porat definía la modalidad que nos concierne en los siguientes términos:

Parody $=$ An alleged representation, usually comic, of a literary text or other artistic object - i.e., a representation of a "modelled reality," which is itself already a particular representation of an original "reality". The parodic representations expose the model's conventions and lay bare its devices through the coexistence of the two codes in the same message (1979: 247).

También Pozuelo Yvancos (2007) se acerca a esta postura, pero sustituye la descripción del fenómeno como "representación de una realidad modelada" por la de "representación o imagen de una textualidad". Esto se traduce en el desplazamiento del interés filológico a una concepción de la parodia - y de la literatura- como construcción lingüística:

es fundamental que el texto parodiado sea también algo más que un texto, sea en cierto sentido representación o imagen de una textualidad que comparta el mismo sufijo que autoridad [...]. [D]e ahí la importancia que tendrá [...] en el desarrollo de la parodia la hipertrofia del texto objeto de la parodia (2007: 268).

Así pues, el texto paródico nace de una intertextualidad y mantiene ese tono gracias a que se queda impregnado de los rasgos de estilo de su fuente. Se vincula la reproducción de una textualidad con los patrones de autoridad porque la parodia tiende a buscar un referente ampliamente conocido. La aceptación de la representatividad del hiporreferente es connatural a la parodia. El texto paródico admite las virtudes de su objetivo referencial, pues precisamente lo selecciona por eso, pero, al mismo tiempo, pretende jugar con él o desenmascarar sus convenciones (temáticas, formales, ideológicas, etc.). Blesa (1994) anota con perspicacia la ambigüedad con la que opera este modo, pues la parodia fusiona el homenaje y el reproche. Este aspecto se observa claramente en "El poema (variación sobre un tema de JRJ)", de Víctor Botas, quien defiende el prosaísmo lírico como eje de su poética: "No le toques ya más / que así es la prosa" (2012: 317). También se aprecia en "Carolina", de Almudena Guzmán, que parodia "De invierno", de Rubén Darío:

\footnotetext{
Rubén era poeta

y ya se sabe cómo son los poetas, pero yo nunca he tenido un abrigo

de marta cibelina

ni un solo biombo del Japón.

Mi gato no es de angora,

es callejero,

y para qué quiero una chimenea

si en casa hay calefacción central.
} 
Queda la puntualización más importante:

no nevaba en París,

llovía en Roma.

Pero besarme sí que me besó (2012: 377).

Ahora bien, aunque la hipertrofia y la importancia de la interpretación ayuden a elaborar el contorno de la parodia, la intencionalidad es el criterio que desempeña un papel principal. De hecho, es el primer paso para la construcción de esta modalidad. Por otra parte, hay que resaltar que la ironía y la intertextualidad a veces no caracterizan exclusivamente a la parodia, sino que la sátira también puede recurrir a estos procedimientos. Hutcheon explica que la confusión conceptual entre sátira y parodia radica en la limitada interpretación del prefijo griego para. Si bien se había asumido como 'contra', era necesario recordar su valor de 'junto a'. El texto paródico no siempre ridiculiza ni satiriza al parodiado; sin embargo, muchos críticos han observado que son modalidades cercanas cuando se cuestiona el estilo del hiporreferente (Booth, 1986; Domínguez Caparrós, 1994; Ruiz Gurillo, 2012). En su punto de partida, es decir, en la intencionalidad, se forja la diferencia entre sátira y parodia, pero también se naturalizan unos contactos que llegan a desencadenar modalidades mixtas.

La parodia, en tanto que ironía intertextual, puede tener un valor satírico añadido; esto es, la parodia es capaz de ironizar sobre un discurso previo y su contenido - la realidad modelada o la textualidad-, pero en ocasiones admite el valor satírico de crítica hacia el exterior del discurso - la realidad no modelada - o hacia el propio discurso. Sucede lo mismo a la inversa hasta el punto de que "satire uses parody as a vehicle for ridiculing the vice sor the follies of humanity” (Hutcheon, 2000: 54). La sátira, entonces, por sí sola no es intertextual. La sátira se define por su objetivo — la realidad no modelada - y por su impulso generador - la crítica a partir de algunos juicios morales- - Un poema de carácter satírico-paródico es "Glosa a Celaya", de Roger Wolfe, quien, para criticar la ingenuidad de la poesía política y las leyes del mercado, recurre a la parodia del archiconocido texto de Celaya y de un eslogan del Banco de Santander:

\author{
La poesía es \\ un arma \\ cargada de futuro. \\ Y el futuro \\ es del Banco \\ de Santander (2008: 262).
}

En consecuencia, si la parodia se sirve de las operaciones de la sátira y si esta última acude a las técnicas de la otra modalidad, es factible reconsiderar los criterios teóricos que las aíslan y contemplar la posibilidad de que en ocasiones compartan rasgos. BenPorat anunció tres conceptos "indirectly satirical parody", "directly satirical parody" y "[a] combination of 1 and 2" (1979: 247). Todo ello se simplificaría siguiendo el punto 
de vista de Galván y González Doreste, quienes sintetizan las tres nociones anteriores en la "parodia satírica" y en la "sátira paródica" (1994: 115). Si la confusión entre la sátira y la parodia se origina en que ambas emplean la ironía como estrategia, consideramos, por ende, que en este caso el orden de los factores sí altera el producto: la parodia satírica es la suma de ironía, intertextualidad y vindicación, mientras que la sátira paródica resulta de unir ironía, vindicación e intertextualidad (Baños Saldaña, 2017). La operación paródica implica revisar un texto anterior. Esa mirada nueva hacia él suele ser lúdica, pero también puede implicar crítica, lo que ya nos sitúa en el terreno de la modalidad satírica. Desde la orilla contraria, la sátira puede recurrir a la hipertrofia semántica o estilística de la parodia; con todo, para la consecución de su objetivo no necesita llevar los procedimientos paródicos al extremo.

Estas dos modalidades, pensando que la trascendencia relacional de la sátira se halla en su vertiente paródica, se erigen en la máxima representación de los patrones transreferenciales que aúnan el contacto directo - la intertextualidad o la intermedialidad - con el mantenimiento de la tensión interdiscursiva. No pertenecen ni a uno ni a otro nivel, sino que se sitúan en el quicio de ambos, y eso es, precisamente, lo que los hace realmente apropiados y moldeables para la expresión de ideas poéticas. De ahí viene la identificación de estas modalidades con los procesos autorreflexivos. Caselli entrevió esta naturaleza de lo paródico: "è dunque un prezioso dispositivo inter- e metatestuale, capace di svelare la natura del testo come interazione di altri testi e di smitizzare la capacità reificante e l'illusorio potere mimetico dei modelli litterari" (1996: 88); sin embargo, no precisó su ubicación como fenómeno transreferencial. Dicho con otras palabras, la parodia, en general, y la sátira paródica, en particular, no son dispositivos intertextuales y metatextuales, sino que están entre un aspecto y otro: ese es su ritmo y su razón de ser literarios. Estas dos modalidades no se pueden reducir a intertextualidad porque superan sus límites: siempre andan a medio camino entre la intertextualidad y la interdiscursividad metatextual. No son el resultado de la suma de contacto entre referentes y de reproducción de una textualidad, como si se dieran por separado, sino que se explican como engarce de ambos.

\subsection{Relaciones interdiscursivas: la transreferencialidad de esquemas formales y de contenido (pastiche, interfiguralidad y variantes tematológicas)}

La interdiscursividad, término acuñado por Cesare Segre (2014), se ha empleado posteriormente de diferentes maneras. Algunos críticos han utilizado el concepto para englobar las conexiones del texto literario con otros sistemas semiológicos - sobre todo, con los visuales - (Martínez Fernández, 2001); sin embargo, la interdiscursividad, desde su origen, también servía para la investigación de las operaciones de trasvase de patrones organizativos. Lo aclara acertadamente Lanz al señalar que a través de esta noción se estudia "la reelaboración [de] esquemas complejos tanto formales como de pensamiento" (2009: 4). 
Desde la teoría de la transreferencialidad, adaptaremos esta segunda vertiente al tercer grado de las relaciones que admiten los textos literarios. De este modo, el concepto de Segre se vuelve más pertinente que nunca, pues hemos solventado los solapamientos que se producían con los contactos por intermedialidad. Quiere esto decir que el interés referencial de la interdiscursividad se halla en que su referente no se ubica en un hecho artístico concreto - libro, pintura, música-, sino en una generalización que se comprende como una codificación cultural estable y, por lo tanto, reconocible por el lector. Segre (2014) ya anunció esta doble naturaleza de los textos, que no solo se generan por la escritura, sino que además se construyen a partir de una serie de materiales antropológicos que, a la vez, se proyectan como enunciados; es decir, la literatura llega a los lectores como construcción lingüística particular y como carga significativa individual inscrita en un flujo de elementos codificados o de discursos que han sido denominados como tradición:

Per dirlo in altri termini (che anticipano quanto argomenterò dopo) nel caso de la fonte il testo si richiama a un altro testo, in quello del dialogismo generale il testo si richiama ad altri enunciati non firmati o di cui non è nota la firma. [...] Noi diremo che i materiali eterogenei presenti nella lingua appartengono a enunciati (o secondo un'altra terminologia, a discorsi) precedenti. Questi enunciati possono anche esser chiamati testi [...] ma io credo sia conveniente distinguere tra testi concreti [...] ed enunciati verbali non riconducibile —o non necessariamente riconducibili- a testi concreti (2014: 576-577).

Una sucinta muestra de las categorías que responden a la interdiscursividad exige, por lo menos, mencionar el pastiche, la interfiguralidad y las variantes tematológicas. Como se observa, en todas ellas predomina la extensión sobre la intensión; esto es, los procedimientos interdiscursivos brotan de una concreción generalizada. Piénsese en el primero de los tres a los que hemos aludido, el pastiche. Este se ha acotado teóricamente como una imitación (Genette, 1989; Jameson, 1991). Su especificidad se encuentra en que reproduce un esquema estilístico, por lo que tradicionalmente se ha clasificado como proceso formal, a pesar de que la mímesis de un estilo conlleva en ocasiones la apropiación de sus ejes temáticos. Se entiende, pues, como interdiscursividad porque, a diferencia de la intertextualidad o de la parodia, no sitúa su objetivo en un texto determinado, sino que lo enfoca en una globalidad. No hablaríamos, pues, de un pastiche sobre el soneto 23 de Garcilaso. En todo caso será una imitación de la expresión garcilasiana, de la retórica del collige, virgo, rosas o, más amplio aún, de la poesía española renacentista. Se advierte, en consecuencia, que el pastiche es una categoría cercana a la parodia, pero se puede comprobar que no actúa como esta modalidad transreferencial.

Otra técnica de transreferencialidad de esquemas formales y de contenido es la interfiguralidad. La "interfigurality”, propuesta por Müller (1991), trata de ocupar el vacío terminológico en los estudios literarios en lo que respecta a las conexiones entre personajes. Como ha sido costumbre, el concepto se refugia en el prestigio de la intertextualidad olvidando, una vez más, las particularidades de cada vínculo: “[t]he 
interrelations that exist between characters of different texts represent one of the most inportant dimensions of intertextuality" (1991: 101). Si se admitiera que la interfiguralidad deviene en un reducto intertextual, se estaría reconociendo que su fuerza relacional reside en el préstamo del nombre. Y no es así: lo más importante de la interfiguralidad se alberga en la reproducción de un esquema de conducta, como puede ilustrarlo la concordancia de Emma Bovary con don Quijote, entre otros muchos ejemplos. Pese a todo, podría compartir con la intertextualidad la señalización de una hiporreferencia concreta; ahora bien, la mayoría de comparticiones interfigurales recurren a personajes que sobrepasan los límites de un texto, como sucede con las reapariciones de don Juan, de Fausto o de las figuras mitológicas.

La interfiguralidad, en consecuencia, repercute sobre el contenido y sobre la estructura del hiperreferente. Esta categoría gana productividad en el ámbito teatral o en el narrativo, aunque también aparece con naturalidad en poesía. A modo de prueba, piénsese en la incorporación de la onomástica latina en los epigramas contemporáneos o, también en relación con esto, en el uso de Lesbia como referente. En este último caso no suele importar de qué texto de Catulo se extrae el nombre, sino las coordenadas de sentido que genera: mencionar a Lesbia puede implicar la destinación del texto a una amante o su tematización-, la exaltación de la pasión, el erotismo, la tendencia a la concisión epigramática, etcétera.

Finalmente, consideramos dentro de la transreferencialidad de esquemas formales y de contenido las variantes tematológicas. Con este sintagma se engloban diversas partes de los estudios comparatísticos que han puesto de relieve la dinamicidad de elementos supratextuales, entendidos, entonces, como la continuación de codificaciones culturales propias de la inventio. Nos referimos, pues, a temas, motivos, recursos literarios que ejercen de síntomas estilísticos (metáforas, metonimias, alegorías, símbolos, etc.), tópicos, la interdiscursividad germinativa ${ }^{11} \mathrm{o}$ las transposiciones temáticas de Genette transdiegetización, transpragmatización, transmotivación y transvalorización-.

\section{CONCLUSIONES: LA TEORÍA DE LA LITERATURA FRENTE A LA COMUNICACIÓN LITERARIA}

Los tres niveles de análisis transreferencial facilitan la comprensión de la dinamicidad de los textos literarios. Los hechos culturales no se archivan ni permanecen estáticos, sino que perviven gracias a su capacidad para seguir explicando aspectos de la condición humana. Y, por ello, los escritores tienden a ponerlos en relación y a actualizarlos desde

\footnotetext{
${ }^{11}$ De acuerdo con Pozuelo Yvancos, introductor del término, el análisis de la interdiscursividad germinativa consiste en "[b]uscar en autores ideas clave o fuerzas motrices que hayan nacido de unos discursos o textos anteriores (sean o no literarios, o sean o no cita concreta explícita) que los autores hayan desarrollado a su modo, de manera que la obra o las obras pueden leerse como desarrollos de ese embrión. El discurso o texto origen actúa como fuente generativa, pero se comporta ya como estímulo de una creatividad nueva, que, aun siendo deudataria, se halla transformada y evolucionada hacia lugares no previstos, de manera que la simple cita o referencia de la fuente no agotaría su fertilidad hermenéutica" (2019: 674).
} 
la expresión personal. En este sentido, una tipología como la transreferencialidad, que nace preocupándose por los trasvases artísticos contemporáneos, garantiza la comprensión global de las relaciones que un texto establece con múltiples referentes. Sus tres niveles - contactos directos, modalidades e interdiscursividad-, con sus respectivas subcategorías, le permiten al crítico acceder a la relevancia cognitiva de los vínculos que subyacen en las obras literarias. Así pues, esta tipología variada y precisa contribuye eficazmente al estudio de la creatividad humana, de la que no se puede dar cuenta a través de una generalización del concepto de intertextualidad o, peor aún, a través de la desconfianza en los repertorios conceptuales.

Con todo, no debe quedarse al margen la prudencia teórica que se deriva de la complejidad de nuestro objeto de estudio: numera stellas si potes. En efecto, la experiencia en la investigación de las prácticas artísticas nos demuestra que pretender restringir la riqueza de lo literario a un breve catálogo es una tarea tan insondable como saber el número exacto de estrellas que hay en el cielo. No es eso lo que pretende la tipología de la transreferencialidad; al contrario, lo que se persigue es demostrar que disponemos de un sistema organizado para analizar los fenómenos presentes y para, de la misma manera, dar cuenta de las mixturas y de las hibridaciones relacionales con las que se construyen las obras literarias. En otros términos, la propuesta transreferencial se apega a las aportaciones teóricas formuladas hasta la fecha. Mediante su adaptación a un marco cognitivo-cultural y mediante la estructuración de estas en un compendio teórico amplio, a la vez que, a través de la lima de algunos solapamientos o desvíos conceptuales, se logra una tipología compacta capaz de explicar los textos del pasado y los productos literarios actuales.

\section{REFERENCIAS BIBLIOGRÁFICAS}

Álvarez, J. M. (2002). Museo de cera. Sevilla: Renacimiento.

BAGUÉ QuílEZ, L. (2012). "Introducción al concepto de écfrasis". En Metodologías comparatistas y literatura comparada, P. Aullón de Haro (ed.), 231-240. Madrid: Dykinson.

Bagué Quílez, L. Y Rodríguez Rosique, S. (2013). "La ironía en segundo grado: (in)versiones discursivas en la poesía española reciente". Bulletin of Hispanic Studies 90.3, 295-310.

Bajtín, M. (1986). Problemas de la poética de Dostoievski. México: Fondo de Cultura Económica.

BAllaRt, P. (1994). Eironeia: la figuración irónica en el discurso literario moderno. Barcelona: Quaderns Crema.

(2005). "La musa irónica. Recursos distanciadores en los poetas españoles contemporáneos". Texte. Revue Critique et de Théorie Littérarie 35-36, 235-295. 
BAÑOS SALDAÑA, J. A. (2017). "La pervivencia de las poéticas juanramonianas. Ironía, intertextualidad y espacios discursivos en la lírica española contemporánea”, $L a$ Nueva Literatura Hispánica 25, 167-188.

(2019). Desautomatización y posmodernidad en la poesía española contemporánea.

La tradición grecolatina y la Biblia. Córdoba: Universidad de Córdoba.

(2020). "Metapoesía y publicidad: el poeta en la sociedad de consumo". Pasavento:

Revista de Estudios Hispánicos VIII, 157-176.

BARTHES, R. (1980). S/Z. Madrid: Siglo XXI.

Ben-Porat, Z. (1979). "Method in Madness: Notes on the Structure of Parody, Based on MAD TV Satires". Poetics Today 1-2, 245-272.

BIANCHI, M. (2017). "Poesía y transtextualidad, desde los cincuenta hasta hoy: razones de un monográfico y notas contextuales”. La Nueva Literatura Hispánica 21, 920.

Blesa, T. (1994). "Parodia: literatura". En Actas del IX Simposio de la Sociedad Española de Literatura General y Comparada. Tomo II, VV. AA., 57-65. Zaragoza: Universidad de Zaragoza.

Booth, W. C. (1986). Retórica de la ironía. Madrid: Taurus.

Botas, V. (2012). Poesía completa. Sevilla: Isla de Siltolá.

BRUHN, S. (2011). "Reflexiones sobre écfrasis musical". En Entre artes, entre actos: écfrasis e intermedialidad, S. González Aktories e I. Artigas Albarelli (eds.), 5160. México: Bonilla Artigas.

CASElli, D. (1996). "Rifunzionalizzare la nozione di intertestualità: alcune proposte italiane”. Strumenti e Critici 80, 75-92.

DOMíngUEZ CAPARRÓs, J. (1994). "Sobre funciones literarias de la parodia". En Actas del IX Simposio de la Sociedad Española de Literatura General y Comparada, VV.AA., tomo II, 97-105. Zaragoza: Universidad de Zaragoza.

DuCROT, O. (1986). El decir y lo dicho: polifonía de la enunciación. Barcelona: Paidós.

GALVÁn, F. y GonZÁlez Doreste, D. M. (1994). "El uso contemporáneo de parodia". En Actas del IX Simposio de la Sociedad Española de Literatura General y Comparada. Tomo II, VV. AA., 111-119. Zaragoza: Universidad de Zaragoza.

GARCÍA-RodríGueZ, M. J. (2021). Teoría de la parodia. Madrid: Visor Libros.

Genette, G. (1989). Palimpsestos. La literatura en segundo grado. Madrid: Taurus. (2001). Umbrales. México: Siglo XXI.

GERCHUNOFF, S. (2019). Ironía On. Una defensa de la conversación pública de masas. Barcelona: Anagrama.

Giovine, M. A. (2011). "Écfrasis y poesía visual: dos acercamientos a la iconotextualidad". En Entre artes, entre actos: écfrasis e intermedialidad, S. González Aktories e I. Artigas Albarelli (eds.), 69-78. México: Bonilla Artigas.

GonzÁLEZ, Á. (2014). "Entrevista a Ángel González". Disponible en línea: https://www.youtube.com/watch?v=nXdNsmZ2YrI [10/02/2020].

GuZMán, A. (2012). El jazmín y la noche. Poesía reunida (1981-2011). Madrid: Visor. 
Hutcheon, L. (2000). A Theory of Parody. The Teachings of Twentieth-Century Art Forms. Chicago: University of Illinois Press.

JAMESON, F. (1991). El posmodernismo o la lógica cultural del capitalismo avanzado. Barcelona: Paidós.

LANZ, J. J. (2009). “Juegos intertextuales en la poesía española actual: algunos ejemplos”. Anuario Brasileño de Estudios Hispánicos 19, 49-66.

LaRa Rallo, C. (1991). Las voces y los ecos. Perspectivas sobre la intertextualidad. Málaga: Analecta Malacitana.

LOTMAN, Y. M. (1978). Estructura del texto artístico. Madrid: Istmo.

LuQue, A. (2003). Camaradas de Ícaro. Madrid: Visor Libros.

MARTínez FERnÁndEZ, J. E. (2001). La intertextualidad literaria. Madrid: Cátedra.

MÜLLER, W. G. (1991). "Interfigurality. A Study on the Interdependence of Literary Figures”. En Intertextuality, H. Plett (ed.), 101-121. Berlin / New York: Walter de Gruyter.

NAVARRO, D. (2004). “Al lector”. En Intertextualität. La teoría de la intertextualidad en Alemania, D. Navarro (ed.), 5-8. La Habana: UNEAC

Pimentel, L. A. (2003). "Écfrasis y lecturas iconotextuales”. Poligrafías. Revista de Teoría Literaria y Literatura Comparada 4, 205-215.

Plett, H. (2004). "Intertextualidades". En Intertextualität. La teoría de la intertextualidad en Alemania, D. Navarro (ed.), 50-84. La Habana: UNEAC.

Ponce CÁrdenAs, J. (2014). Écfrasis: visión y escritura. Madrid: Fragua.

Pozuelo Yvancos, J. M. (2007). Desafíos de la teoría: literatura y géneros. Mérida: El Otro, El Mismo.

(2019). "Interdiscursividad: cine y literatura en Javier Cercas". En Docta y sabia Atenea. Studia in honorem Lía Schwartz, S. López Poza, N. Pena Sueiro, M. de la Campa, I. Pérez Cuenca, S. Byrne y A. Vidorreta (eds.), 671-682. A Coruña: Universidade da Coruña.

REYes, G. (1984). Polifonía textual. La citación en el relato literario. Madrid: Gredos.

RIFFATERRE, M. (2000). "La ilusión de écfrasis". En Literatura y pintura, A. Monegal (ed.), 161-185. Madrid: Arco / Libros.

Ruiz GuRILlo, L. (2012). La lingüística del humor en español. Madrid: Arco / Libros.

SEgRe, C. (2014). Opera Critica. Milano: Mondadori.

SPERBER, D. Y WILSON, D. (1994). La relevancia: comunicación y procesos cognitivos. Madrid: Visor Libros.

SPITZER, L. (1962). "The Ode on a Grecian urn or Content vs. Metagrammar". En Essays on English and American Literature, L. Spitzer, 69-97. Princeton: Princeton University Press.

Velarde SÁNCHEZ, E. (2018). "Écfrasis musical en tres poemas de Ángel González". Inventio 33, 205-215. 
WAGNER, P. (2000). "Ekphrasis, Iconotexts, and Intermediality - the State(s) of the Art(s)". En Icons - Texts - Iconotexts. Essays on Ekphrasis and Intermediality, P. Wagner (ed.), 1-41. Berlin / New York: Walter de Gruyter.

Wolfe, R. (2008). Noches de blanco papel (Poesía completa 1986-2001). Barcelona: Huacanamo.

El/la firmante del artículo se responsabiliza de las licencias de uso de las imágenes.

Fecha de recepción: 16/01/2021

Fecha de aceptación: 21/05/2021 